\title{
Chemistry of Buttermilk Solid Antioxidant Activity
}

\author{
P. Y. Y. Wong and D. D. Kitts* \\ ${ }^{*}$ Food, Nutrition and Health \\ Univ. of British Columbia, 6650 N.W. Marine Drive \\ Vancouver, British Columbia, Canada V6T 1 Z4
}

\begin{abstract}
Antioxidant activity of buttermilk solids was assessed by analyzing for relative reducing activity, sulfhydryl content, and ferrous and ferric iron binding affinity. These experiments were followed by monitoring the affinity of buttermilk solids to scavenge both hydroxyl and peroxyl radicals in vitro. Notable relative reducing activity of buttermilk solids to L-ascorbic acid ( 43.80 to $85.85 \%$ over a range of 5.0 to $10.0 \mathrm{mg}$ ) was attributed in part to the sulfhydryl content $(28.8 \mu M)$. Buttermilk solids sequestering activity was greater for ferrous than ferric ion. These chemical properties of buttermilk solids corresponded to a significant affinity to scavenge Fenton-induced hydroxyl radical over a range of 5 to $10 \mathrm{mg}$. A significant affinity of buttermilk solids to protect against lipid peroxidation, tested using an in vitro model lipid system, was also observed at both 0.1 and $0.2 \%$ (wt/vol). These findings demonstrated that buttermilk solids possess significant antioxidant activity, thereby suggesting potential use as a valueadded ingredient for stabilizing food matrixes against lipid peroxidation reactions.
\end{abstract}

(Key words: reducing activity, sulfhydryl group, hydroxyl radical scavenging, antioxidant activity)

Abbreviation key: BMS = buttermilk solids, DTNB $=5,5^{\prime}$-dithiobis-2-nitrobenzoic acid, $\mathbf{L M W F}=$ low molecular weight fraction, MMWF = medium molecular weight fraction, HMWF = high molecular weight fraction.

\section{INTRODUCTION}

Lipid oxidation of monounsaturated and polyunsaturated fatty acids in foods during processing and storage is a major concern to the food industry. The oxidation of unsaturated fatty acids result in the formation of peroxides, which are susceptible to further decomposition to secondary oxidation byproducts, such as short-

Received April 17, 2002.

Accepted April 17, 2002.

Corresponding author: D. D. Kitts; e-mail: ddkitts@interchange. ubc.ca. chain aldehydes and ketones. The presence of these molecules, reacting with oxygenated compounds in foods, will adversely affect flavor, taste, nutritional value and overall quality (Vercellotti et al., 1992). Many synthetic antioxidants such as butylated hydroxytoluene or tert-butylhydroquinone and metal sequestering agents such as EDTA effectively retard the onset of lipid oxidation. Nevertheless, due to food safety concerns over the use of these synthetic antioxidants, alternative sources derived from plant and animal origins have received considerable attention. Previous studies undertaken in our laboratory with natural antioxidant, have demonstrated effectiveness at reducing lipid oxidation. In particular, Wijewickreme and Kitts (1997, 1998) have observed the antioxidant activity of Maillard reaction products in linoleic acid emulsion, which was also observed later in a flour-lipid mixture. Furthermore, Jaswir et al. (2000a, 2000b) demonstrated the antioxidant activity effect of an oleoresin rosemary, sage, and citric acid mixture in palm olein during repeated deep-fat frying of potato chips. These results demonstrated the potential for application of natural food ingredients as stabilizers of lipid rich foods.

The antioxidant potential of proteins derived from dairy products is known (Allen and Wrieden, 1982; Colbert and Decher, 1991; Stuchell and Krochta, 1995; Maté et al., 1996). Allen and Wrieden (1982) showed that casein had antioxidant activity at concentrations relevant to bovine milk sources, whereas whey was less effective at similar concentrations. Antioxidant activity of milk proteins was proposed in part to be due to the sequestering of iron and copper metals by the phosphoseryl residues located on the surface of the casein micelle. Other workers have suggested that whey proteins donate hydrogen to reduce free radicals (Colbert and Decker, 1991), and that free sulfhydryl groups from cysteine are effective at inhibiting lipid autoxidation (Taylor and Richardson, 1980a, 1980b). Furthermore, the presence of antioxidant enzymes (e.g., superoxide dismutase and catalase) and nonenzymatic antioxidants (e.g., tocopherols, carotenoids, citrate, phosphate, and ascorbic acid) in milk may also contribute to the overall antioxidative effect observed by others (Richardson and Korycka and Dahl, 1983). However, xanthine 
oxidase, derived from cream, has been demonstrated to induce lipid oxidation in a linolenic acid model system by the production of superoxide anion (Kellogg and Friderich, 1975). The actual significance of xanthine oxidase prooxidant activity to promote oxidation in foods may vary, depending on the presence of superoxide dismutase enzyme that scavenges superoxide anion.

Buttermilk is the liquid byproduct derived from the churning of cream into butter. It has a composition similar to that of skim milk, therefore, containing both casein and whey proteins in addition to a small amount of fat. In 1967, a total of 153 million pounds of buttermilk and dried buttermilk solids (BMS) were produced in the USA alone (Nutting, 1970); however, only a fraction was reported as being reutilized for human consumption by replacing skim milk powder in baked goods and dairy products. This situation still prevails today. Unlike whey, buttermilk has no novel applications such as a protein supplement, a functional ingredient or an antioxidant. The objectives of this study were therefore to evaluate the antioxidant potential of a spray-dried BMS and to identify the chemistry underlying the mechanism of observed antioxidant activity.

\section{MATERIALS AND METHODS}

\section{Materials}

Spray-dried BMS and whey powder were donated by Dairyworld Foods (Burnaby, BC, Canada) and stored in a polyethylene bag at $4^{\circ} \mathrm{C}$ until used. Feedgrade menhaden fish oil refined with alkali, pressed, bleached and nondeodorized was obtained from Zapta Haynie Corp. (Reedville, VA) and refrigerated until used. Sodium dihydrogen ortho-phosphate, potassium ferricyanide, ferrous chloride $\left(\mathrm{FeCl}_{2}\right)$, ferric chloride $\left(\mathrm{FeCl}_{3}\right)$ and Lascorbic acid were obtained from $\mathrm{BDH}$ Chemicals Co (Toronto, ON, Canada). Sodium phosphate, sodium hydroxide, ethanol, trichloroacetic acid, hydrogen peroxide, and ammonium thiocyanate were purchased from Fisher Scientific Co. (Fair Lawn, NJ). Tween 20 was obtained from Difco Laboratories (Detroit, MI). The butylate hydroxy toluene, BHA, 5,5'-dithiobis-2-nitrobenzoic acid (DTNB), $\mathrm{Na}_{2}$-EDTA, HEPES, Tris base, Tris $\mathrm{HCl}$, and thiobarbituric acid were purchased from Sigma Chem. Co. (St. Louis, MO). Deoxyribose was from Applied Sci. Lab. (PA).

\section{Iron Distribution in BMS}

Distribution of iron in BMS was determined by separating the BMS into various molecular weight fractions and analyzing each fraction for total iron. Approximately $2 \mathrm{~g}$ of BMS was dissolved in $20 \mathrm{ml}$ of distilled deionized water, thoroughly mixed and centrifuged at
$6000 \mathrm{rpm}$ for $1 \mathrm{~h}$ at $6^{\circ} \mathrm{C}$ and $\mathrm{pH}$ of 6.6 . The resultant precipitate was collected and labeled as high molecular weight fraction (HMWF). The remaining supernatant was transferred to a MSI Ultrafuge centrifuge tube (containing a filter with a molecular weight cut-off at $30 \mathrm{kDa}$ ) (Fisher Scientific Co., Fair Lawn, NJ) and was further centrifuged at $6000 \mathrm{rpm}$ for $45 \mathrm{~min}$ at $6^{\circ} \mathrm{C}$. Both filtrate (labeled as low molecular weight fraction (LMWF)) and retente (labeled as medium molecular weight fraction (MMWF)) was collected separately. All three fractions were analyzed for total iron utilizing nitric-acid-hydrogen peroxide digestion, followed by iron analysis with Flame Atomic Absorption/Emission Spectroscopy.

\section{Sulfhydryl Content}

Sulfhydryl content of BMS and whey was measured using the method of Ellman (1959). BMS and whey (0.1 to $10 \mathrm{mg}$ ) was dissolved in $1 \mathrm{ml}$ of distilled deionized water and mixed with DTNB [39.6 mg in $10 \mathrm{ml}$ of phosphate buffer (0.2 M, pH 7.0)]. Absorbance readings were taken at $412 \mathrm{~nm}$ and the sulfhydryl content $(\mu M)$ was calculated according to the following:

$$
\text { Sulfhydryl content }(\mu M)=\frac{\mathrm{A}_{412 \mathrm{~nm}}}{\varepsilon} \times \mathrm{D},
$$

where

$$
\begin{aligned}
\mathrm{A}_{412 \mathrm{~nm}} & =\text { absorbance at } 412 \mathrm{~nm}, \\
\varepsilon & =\text { extinction coefficient }=13,600 / \mathrm{M} / \mathrm{cm}, \text { and } \\
\mathrm{D} & =\text { dilution factor }=1.7 / 1 .
\end{aligned}
$$

\section{Relative Reducing Activity}

The relative reducing activities of BMS and whey were determined according to the method of Oyaizu (1986), as described by Yen and Chen (1995). BMS, whey, and L-ascorbic acid ( 0.1 to $10 \mathrm{mg}$ ) were dissolved in $1 \mathrm{ml}$ of distilled deionized water and mixed with 2.5 $\mathrm{ml}$ of phosphate buffer $(0.2 \mathrm{M}, \mathrm{pH} 6.6)$ and $2.5 \mathrm{ml} 1 \%$ potassium ferricyanide $\left(\mathrm{K}_{3} \mathrm{Fe}(\mathrm{CN})_{6}\right)$. The mixture was incubated at $50^{\circ} \mathrm{C}$ for $20 \mathrm{~min}$. A volume of $2.5 \mathrm{ml} 10 \%$ trichloroacetic acid was then added to the mixture and centrifuged at $3000 \mathrm{rpm}$ for $10 \mathrm{~min}$. A $1-\mathrm{ml}$ aliquot of supernatant was mixed with $1 \mathrm{ml}$ of distilled deionized water and $0.2 \mathrm{ml}$ of $\mathrm{FeCl}_{3}(0.1 \%)$, and the absorbance was measured at $700 \mathrm{~nm}$. Increasing absorbance at 700 $\mathrm{nm}$ was interpreted as increasing reducing activity.

\section{Iron Binding}

Ferrous and ferric iron binding was determined using a modification of the thiocyanate method of Duh and 
Yen (1995) as described in Wong and Kitts (2001). Aliquot of $\mathrm{FeCl}_{2}$ or $\mathrm{FeCl}_{3}$ solutions $(1.0,2.5$, and $5.0 \mathrm{mM}$ ) and BMS (0.1 to $10 \mathrm{mg}$ in $1 \mathrm{ml}$ of distilled deionized water) were dissolved in ethanol (75\%), and incubated with $\mathrm{H}_{2} \mathrm{O}_{2}(0.1 \%)$. One hundred microliters of $30 \%$ ammonium thiocyanate was added to the reactant mixture, which was read at an absorbance of $500 \mathrm{~nm}$ to determine total soluble ferric in solution. The addition of $\mathrm{H}_{2} \mathrm{O}_{2}$ to the sample was used to convert reduced ferrous $\left(\mathrm{Fe}^{2+}\right)$ to ferric $\left(\mathrm{Fe}^{3+}\right)$. The difference between the amount of iron added and the amount of soluble iron recovered after $1 \mathrm{~h}$ was regarded as the proportion of bound iron. Standard curves for the absorbance of $\mathrm{Fe}^{2+}$ and $\mathrm{Fe}^{3+}$ were determined with 0.1 to $60 \mu \mathrm{g}$ of $\mathrm{FeCl}_{2}$ or $\mathrm{FeCl}_{3}$, respectively. The equation for $\mathrm{Fe}^{2+}$ determination was $\mathrm{y}=0.0262 \mathrm{x}+0.0165\left(\mathrm{R}^{2}=0.999\right)$ and for $\mathrm{Fe}^{3+}$ determination was: $\mathrm{y}=0.0418 \mathrm{x}-0.0085\left(\mathrm{R}^{2}\right.$ $=0.998$ ).

\section{Scavenging of Hydroxyl Radical}

The BMS scavenging capacity for hydroxyl radical was measured according to the modified method of Halliwell et al. (1987). Stock solutions of EDTA (1 mM), $\mathrm{FeCl}_{3}(10 \mathrm{~m} M)$, ascorbic acid $(1 \mathrm{~m} M), \mathrm{H}_{2} \mathrm{O}_{2}(10 \mathrm{mM})$ and deoxyribose $(10 \mathrm{mM})$ were prepared in distilled deionized water. The assay was performed by adding $0.1 \mathrm{ml}$ of EDTA, $0.01 \mathrm{ml}$ of $\mathrm{FeCl}_{3}, 0.1 \mathrm{ml}$ of $\mathrm{H}_{2} \mathrm{O}_{2}, 0.36$ $\mathrm{ml}$ of deoxyribose, $1 \mathrm{ml}$ of BMS ( 0.1 to $10 \mathrm{mg}$ dissolved in distilled deionized water), $0.33 \mathrm{ml}$ of phosphate buffer (50 mM, pH 7.4) and $0.1 \mathrm{ml}$ of ascorbic acid in sequence. The mixture was then incubated at $37^{\circ} \mathrm{C}$ for $1 \mathrm{~h}$. A 1-ml portion of the incubated mixture was mixed with $1 \mathrm{ml}$ of $10 \%$ TCA and $1 \mathrm{ml}$ of $0.5 \%$ TBA (in 0.025 $M \mathrm{NaOH}$ containing $0.02 \% \mathrm{BHA}$ ) to develop the pink chomogen measured at $532 \mathrm{~nm}$. The hydroxyl radical scavenging activity of BMS is reported as \% inhibition of deoxyribose degradation and is calculated as follows:

$$
\% \text { Inhibition }=\frac{\left(\mathrm{Ac}-\mathrm{A}_{\mathrm{BMS}}\right)}{\mathrm{Ac}} \times 100,
$$

where

$\mathrm{A}_{\mathrm{c}}=$ absorbance of control at $532 \mathrm{~nm}$ and $\mathrm{A}_{\mathrm{BMS}}=$ absorbance of BMS samples at $532 \mathrm{~nm}$.

\section{Lipid Oxidation Assay}

The antioxidant activity of BMS and whey was determined in a model lipid emulsion system (Wijewickreme and Kitts, 1997), according to a modified thiocyanate method of Duh and Yen (1995). BMS (0.1 and 0.2\% (wt/ vol), dissolved in $1 \mathrm{ml}$ of distilled deionized water), whey [0.1\% (wt/vol), dissolved in $1 \mathrm{ml}$ of distilled deionized water] and BHT [0.02\% (wt/vol), dissolved in $1 \mathrm{ml}$ of absolute ethanol] were added to solution mixtures containing menhaden fish oil $(0.13 \mathrm{ml})$, Tween 20 (0.13 $\mathrm{ml}), 99 \%$ ethanol $(10 \mathrm{ml})$ and $0.2 \mathrm{M}$ sodium phosphate buffer at $\mathrm{pH} 7.0(10 \mathrm{ml})$. The total volume was made up to $25 \mathrm{ml}$ with distilled deionized water. The sample solution was incubated at $37^{\circ} \mathrm{C}$ in the dark, and the degree of oxidation was measured daily at an absorbance of $500 \mathrm{~nm}$ against $75 \%$ ethanol.

\section{Statistical Analysis}

Each treatment from all experiments was performed in triplicate, sampled twice during analysis, and each experiment was conducted in duplicate. Equality of all population means collected were analyzed by one-way analysis of variance (ANOVA) and Tukey's test was used to identify paired means that are significantly different at a probability of $P<0.05$ using the MiniTab statistical program (MiniTab Inc., PA).

\section{RESULTS AND DISCUSSION}

\section{Iron Distribution in Buttermilk Solids}

Crude powder of BMS contained $2.5 \mathrm{mg}$ of $\mathrm{Fe} / 100 \mathrm{~g}$ of BMS. Iron was distributed in smaller proportions in both the LMWF (e.g., iron salts) at $37.43 \%$ and the HMWF (e.g., casein micelles) fraction at $12.89 \%$, compared with the MMWF (e.g., whey proteins such as lactoferrin) fraction at $49.68 \%$.

\section{Sulfhydryl Group and Reducing Activity}

The sulfhydryl content of BMS and whey powder are shown in Figure 1. BMS was consistently 2 to 3 times less concentrated in sulfhydryl groups than whey. This result is expected, since $\beta$-lactoglobulin in whey contains a large amount of sulfhydryl group in the form of cysteine, which accounts for $50 \%$ of the sulfhydryl group in noncasein protein fraction (Lee, 1983). According to Taylor and Richardson (1980a), the total sulfhydryl group in milk is approximately $50 \mu \mathrm{M}$, and, following complete denaturation of proteins, the total sulfhydryl content will range from 100 to $200 \mu M$. These estimates are higher than our results with BMS $(28.8 \mu M)$, which may be explained by the fact that the BMS used in the present study was a crude powder made from spraydrying pasteurized buttermilk. The dual heating process and the high heat temperature associated with spray-drying could have decreased the total sulfhydryl content in the BMS. Milder heat treatment of milk products on the other hand has been reported to increase sulfhydryl groups (Hutton and Patton, 1952; Patrick 


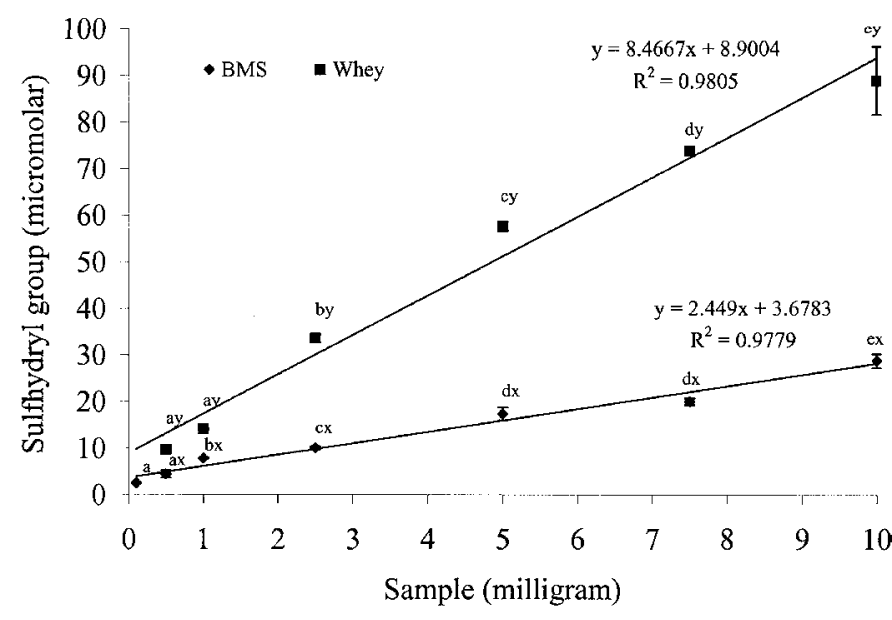

Figure 1. Sulfhydryl (SH) content detected in buttermilk solids (diamond) and whey powder (square). All values represents mean \pm SEM. ${ }^{\mathrm{a}-\mathrm{f}}$ Data within a treatment with different letters are significantly different $(P<0.05)$. ${ }^{\mathrm{xy}}$ Data between treatments with different letters are significantly different $(P<0.05)$.

and Swaisgood, 1976; Taylor and Richardson, 1980a, 1980b).

In this study, reducing activities of the dairy powders and L-ascorbic acid at equal concentrations are illustrated in Figure 2. Increasing the amount of both whey and BMS increased the reducing activities, with whey powder producing a greater increase in reducing activity compared to BMS. In fact, the reducing activity of whey powder at amounts greater than $7.0 \mathrm{mg}$ was greater than that of L-ascorbic acid (e.g., with activities ranging from 111.73 to $150.63 \%$ to that of ascorbic acid). The observed reducing activity of whey positively correlated $(\mathrm{r}=0.9890, P<0.01)$ with the sulfhydryl group. A note of interest is the finding that BMS, which contained relatively less sulfhydryl group than whey, produced a reducing activity that was higher than expected (e.g., activity that was $85.85 \%$ of ascorbic acid). This finding thus suggests that the relative reducing activity observed with BMS was attributed only in part to the total sulfhydryl content, and that proteins or peptides containing free hydroxyl groups could have also contributed to the reducing activity.

\section{Iron Binding}

Trace levels of transition metals, such as iron and copper, are common in foods and can serve as catalysts for production of hydroxyl radical $(\cdot \mathrm{OH})$ via the Fenton reaction when in free form, thus leading to lipid oxidation. Hence the capacity of BMS to sequester transition metals should retard lipid oxidation reactions in foods. The affinity of BMS to sequester $\mathrm{Fe}^{2+}$ and $\mathrm{Fe}^{3+}$ ion is shown in Table 1 . In general, a marked decrease in

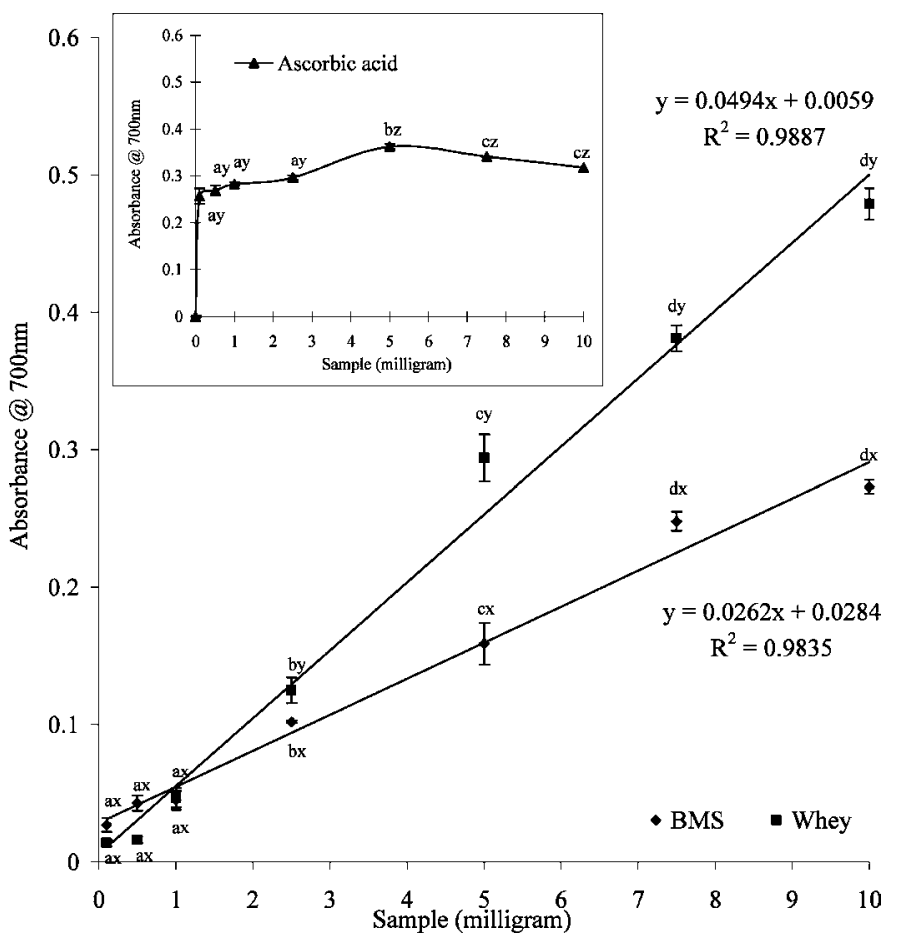

Figure 2. Relative reducing activity (\%) of buttermilk solids (BMS) (diamond) and whey powder (square). All values represents mean \pm SEM. ${ }^{\text {a-g}}$ Data within a treatment with different letter are significantly different $(P<0.05){ }^{\mathrm{x}-\mathrm{z}}$ Data between treatments with different letter are significantly different $(P<0.05)$. Inset: Relative reducing activity (\%) of L-ascorbic acid (triangle).

bound $\mathrm{Fe}^{3+}$, in comparison to bound $\mathrm{Fe}^{2+}$, by BMS was observed. The binding of $\mathrm{Fe}^{2+}$ by BMS was 1.7 to 3.5 times greater than binding of $\mathrm{Fe}^{3+}$. All concentrations of BMS tested exhibited a similar affinity to bind both forms of iron under the conditions tested, except for the significant $(P<0.05)$ increase in the percentage of bound $\mathrm{Fe}^{3+}$ when BMS was increased to $10 \mathrm{mg}$. The BMS effectively bound more $\mathrm{Fe}^{2+}$ when soluble ion was present at $1.0 \mathrm{~m} M$, than at the $2.5 \mathrm{~m} M$ and $5.0 \mathrm{mM}$ concentrations. The relative affinity of BMS for iron ion was greater for $\mathrm{Fe}^{2+}$ than $\mathrm{Fe}^{3+}$ and at lower levels of added iron by the concentrations of BMS examined. Because BMS naturally contains a trace amount of iron (25 $\mu \mathrm{g}$ of $\mathrm{Fe} / \mathrm{g}$ of BMS), the iron-binding activity observed in this study represents the total binding activity of both naturally present irons in milk plus that added to the milk to perform the experiment. The relatively low amounts of $\mathrm{Fe}^{2+}$ bound to BMS, which exceeded 1.0 $\mathrm{m} M$ in most cases, suggested that saturation of bound ion occurred.

Since $\mathrm{Fe}^{2+}$ is the reduced and biologically active form of iron and is involved in many oxidation reactions of food nutrients, the noted affinity of BMS to bind $\mathrm{Fe}^{2+}$ is critical towards any future potential use as a food- 
Table 1. Iron binding of ferrous ion (A) and ferric ion (B) at 1.0, 2.5, and $5 \mathrm{~m} M$ by buttermilk solid.

\begin{tabular}{|c|c|c|c|}
\hline \multirow{2}{*}{$\begin{array}{l}\text { Concentration } \\
(\mathrm{mg} / \mathrm{ml})\end{array}$} & \multicolumn{3}{|c|}{ Bound $\mathrm{Fe}^{2+}(\%)$} \\
\hline & $1.0 \mathrm{~m} M$ & $2.5 \mathrm{~m} M$ & $5.0 \mathrm{~m} M$ \\
\hline \multicolumn{4}{|l|}{ A } \\
\hline 0.1 & $72.85 \pm 5.02^{\mathrm{ax}}$ & $70.44 \pm 0.50^{\mathrm{ax}}$ & $61.20 \pm 0.49^{\text {ay }}$ \\
\hline 0.5 & $71.62 \pm 2.18^{\mathrm{ax}}$ & $88.65 \pm 1.00^{\text {by }}$ & $61.99 \pm 1.00^{\mathrm{az}}$ \\
\hline 1.0 & $68.07 \pm 1.60^{\mathrm{abx}}$ & $59.50 \pm 0.33^{\text {ay }}$ & $60.58 \pm 0.53^{\mathrm{ay}}$ \\
\hline 2.5 & $74.90 \pm 1.11^{\mathrm{ax}}$ & $65.87 \pm 1.75^{\text {ay }}$ & $60.99 \pm 1.64^{\text {ay }}$ \\
\hline 5.0 & $73.95 \pm 1.63^{\mathrm{ax}}$ & $65.87 \pm 0.99^{\mathrm{ay}}$ & $60.11 \pm 1.02^{\mathrm{az}}$ \\
\hline 7.5 & $60.22 \pm 1.98^{\mathrm{abx}}$ & $64.13 \pm 1.71^{\text {ay }}$ & $62.50 \pm 1.11^{\text {ay }}$ \\
\hline 10.0 & $65.19 \pm 3.09^{\mathrm{acx}}$ & $63.91 \pm 1.04^{\mathrm{ax}}$ & $63.04 \pm 0.98^{\mathrm{ax}}$ \\
\hline \multicolumn{4}{|l|}{ B } \\
\hline 0.1 & $26.54 \pm 2.00^{\text {ax }}$ & $17.65 \pm 2.50^{\text {ay }}$ & $24.44 \pm 5.05^{\mathrm{ax}}$ \\
\hline 0.5 & $26.61 \pm 1.85^{\mathrm{ax}}$ & $16.99 \pm 1.15^{\text {ay }}$ & $25.14 \pm 2.00^{\mathrm{ax}}$ \\
\hline 1.0 & $26.47 \pm 1.98^{\mathrm{ax}}$ & $18.22 \pm 2.40^{\mathrm{ay}}$ & $25.94 \pm 1.94^{\mathrm{ax}}$ \\
\hline 2.5 & $28.68 \pm 2.11^{\mathrm{ax}}$ & $26.73 \pm 2.51^{\mathrm{bx}}$ & $29.66 \pm 1.90^{\mathrm{ax}}$ \\
\hline 5.0 & $35.82 \pm 0.55^{\mathrm{bx}}$ & $36.35 \pm 1.96^{\mathrm{cx}}$ & $37.73 \pm 1.07^{\mathrm{bx}}$ \\
\hline 7.5 & $48.67 \pm 0.99^{\mathrm{cx}}$ & $39.03 \pm 2.73^{\text {cy }}$ & $48.11 \pm 1.06^{\mathrm{cx}}$ \\
\hline 10.0 & $52.74 \pm 0.94^{\mathrm{cx}}$ & $41.17 \pm 2.60^{\text {cy }}$ & $51.64 \pm 2.07^{\mathrm{cx}}$ \\
\hline
\end{tabular}

grade antioxidant. In contrast, the presence of $\mathrm{Fe}^{3+}$ in foods usually does not affect lipid oxidation directly; however, in the presence of reducing agents, such as plant flavonoids or ascorbic acid, $\mathrm{Fe}^{3+}$ will be converted back to the $\mathrm{Fe}^{2+}$ form, which often participates in $\cdot \mathrm{OH}$ production and lipid oxidation (Vercellotti et al., 1992). Thus, the affinity of BMS to sequester $\mathrm{Fe}^{3+}$ should also be considered important in controlling oxidative changes in food.

Several researchers have investigated the ability of casein and whey to bind $\mathrm{Fe}^{3+}$ (Basch et al., 1970; Demott and Park, 1974; Demott and Dincer, 1976; Hekmat and McMahon, 1998; McMahon and Brown, 1984). Demott and Park (1978) reported that $87 \%$ of added $\mathrm{Fe}^{3+}$ was bound by raw and pasteurized skim milk and that isoelectric casein and whey were effective at binding to 67.84 and $4.54 \%$, respectively, of the total bound iron. Vaughan and Knauff (1961) have also shown that the relative affinity of $\mathrm{Fe}^{3+}$ to milk proteins was in the order of, $\alpha_{\mathrm{s} 1}$-casein $>\beta$-casein $>$ bovine serum albumin $>\kappa$ casein $>\beta$-lactoglobulin $>\alpha$-lactalbumin. Furthermore, McMahon and Brown (1984) showed that added iron binds to $\alpha_{\mathrm{s} 1}$-casein, $\beta$-casein and $\kappa$-casein in the ratio of 72:21:4. In general, milk fractions containing more phosphoseryl serine groups have the greatest affinity for iron; but carboxyl group of amino acids asparagine and glutamine can bind iron as well (Hekmat and McMahan, 1998).

\section{Scavenging of Hydroxyl Radical}

The Fenton reaction describes the oxidation of $\mathrm{H}_{2} \mathrm{O}_{2}$ by $\mathrm{Fe}^{2+}$ to $\cdot \mathrm{OH}$ and $\mathrm{Fe}^{3+}$. In the model employed in this experiment, the production of $\cdot \mathrm{OH}$ induced oxidation of the deoxyribose, which in turn reacted with TBA to produce a TBA reactive chromophore that was detectable at $532 \mathrm{~nm}$, thus enabling assessment of both antiand pro-oxidant activity of BMS (Table 2). At low levels ranging between 0.1 and $1.0 \mathrm{mg}$ of BMS, BMS promoted oxidation of deoxyribose, which indicates a potential prooxidant activity of BMS at these concentrations. Increasing the BMS concentration to $2.5 \mathrm{mg}$ produced a protective effect towards the $\cdot \mathrm{OH}$-induced oxidation of deoxyribose. A significant $(P<0.05)$ reduction of $\cdot \mathrm{OH}$ was observed at 5 to $10 \mathrm{mg}$ of BMS, demonstrating antioxidant potential against Fenton reaction induced - $\mathrm{OH}$ generation. This finding can be explained in part by the $\cdot \mathrm{OH}$ scavenging activity of sulfhydryl groups, with known reducing activity, in BMS at a critical level of $5.0 \mathrm{mg}$. The biphasic pattern of the antioxidant-prooxidant activity pattern observed with BMS in this aqueous model system is similar to that reported with

Table 2. Percentage of inhibition of hydroxyl radical induced-deoxyribose degradation by buttermilk.

\begin{tabular}{|c|c|c|}
\hline \multirow{2}{*}{$\begin{array}{l}\text { Concentration } \\
(\mathrm{mg} / \mathrm{ml})\end{array}$} & \multicolumn{2}{|c|}{ Buttermilk solids } \\
\hline & Absorbance $^{1}$ & $\%$ Inhibition $^{2}$ \\
\hline 0.0 & $0.677^{\mathrm{a}}$ & $0.00^{\mathrm{a}}$ \\
\hline 0.1 & $0.919^{b}$ & $-35.75^{\mathrm{b}}$ \\
\hline 0.5 & $0.880^{\mathrm{b}}$ & $-29.99^{c}$ \\
\hline 1.0 & $0.813^{\mathrm{a}}$ & $-20.09^{c}$ \\
\hline 2.5 & $0.530^{\mathrm{c}}$ & $21.71^{\mathrm{d}}$ \\
\hline 5.0 & $0.299^{\mathrm{d}}$ & $55.83^{\mathrm{e}}$ \\
\hline 7.5 & $0.297^{\mathrm{d}}$ & $56.13^{\mathrm{e}}$ \\
\hline 10.0 & $0.271^{\mathrm{d}}$ & $59.97^{\mathrm{f}}$ \\
\hline
\end{tabular}

a,b,c,d,e,f Data within a column with different letters are significantly different $(P<0.05)$.

${ }^{1}$ Absorbance was determined at $532 \mathrm{~nm}$.

${ }^{2}$ Negative values represented increased deoxyribose degradation in the presence of buttermilk solids. 


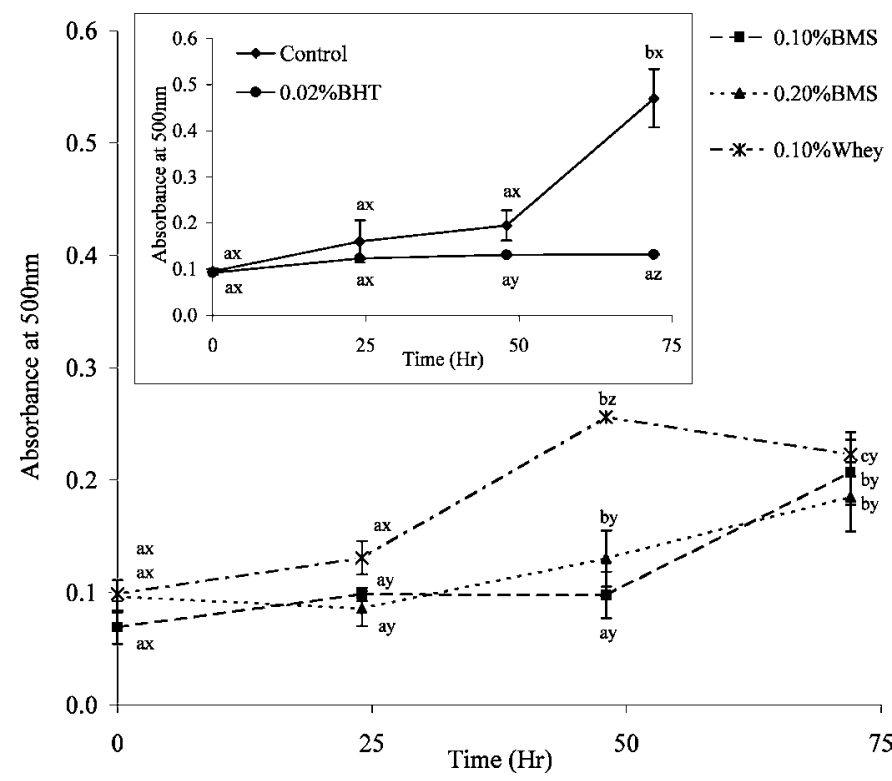

Figure 3. Lipid peroxidation of linoleic acid emulsion system with $0.1 \%$ (square) and $0.2 \%$ (triangle) buttermilks solids (BMS), $0.02 \%$ BHT (circle), $0.10 \%$ whey powder (asterisk) and without antioxidant (diamond). All value represent mean \pm SEM. ${ }^{a-c}$ Data within a treatment with different letters are significantly different $(P<0.05)$.

${ }^{\mathrm{w}-\mathrm{z}}$ Data between treatments with different letters are significantly different $(P<0.05)$.

the reducing activity of ascorbic acid (Mahoney and Graf, 1986).

\section{Lipid Oxidation}

To assess the antioxidant potential of BMS towards inhibiting lipid peroxidation, a model system consisting of menhaden fish oil and two levels of BMS emulsified with Tween 20 in ethanol was used. Whey powder, known for its antioxidant potential (Allen and Wrieden, 1982; Lee, 1983; Stuchell and Krochta, 1995), and BHT were also tested in the same system to compare relative antioxidant activities with BMS. All samples, with exception to BHT enriched fish oil, exhibited a similar lag phase (e.g., 20 to $25 \mathrm{~min}$ ) before the accumulation of lipid peroxide during the storage period, which was typical of the initiation phase of lipid oxidation (Figure 3). Only BHT was effective in delaying the onset of lipid oxidation beyond $75 \mathrm{~h}$. Maximum accumulation of lipid peroxides was detected after $72 \mathrm{~h}$ in both the control and BMS (0.1 and $0.2 \%)$ samples, denoting an overall ineffectiveness of BMS to delay the onset of lipid oxidation at these concentrations. However, the presence of BMS in the emulsion system effectively retarded the severity of lipid oxidation during propagation, as indicated by maximum concentrations of oxidation products at $72 \mathrm{~h}$ of incubation. Whey was less effective than BMS in retarding the severity of lipid oxidation, as measured by maximum accumulation of lipid peroxide over $72 \mathrm{~h}$. The antioxidant activity of the BMS at 0.1 and $0.2 \%$, calculated from the difference between the absorbance of control and treatment, was 55.96 and $60.64 \%$, respectively. Whey was calculated to have an antioxidant activity of $45.56 \%$, which is considerably less than that reported by Colbert and Decker (between 75 and 93\%) (Colbert and Decker, 1991). BHT was determined to have the highest antioxidant activity at $71.93 \%$. The antioxidant activity of BMS observed in this study exceeded that reported in an earlier study by Thompkinson and Mathur (1989). These workers found a difference in peroxide value from polyunsaturated enriched infant formula after 6 mo of storage that corresponded to an antioxidant activity of $12.22 \%$ with the addition of BMS. Based on these findings, they concluded that BMS was not beneficial in controlling the rate of lipid oxidation. Our finding using the emulsion model lipid system described here did not agree with this earlier result.

Thompkinson and Mathur (1989) attributed the observed antioxidant activity of BMS to the presence of phospholipids, and associated activity in donating a proton to a free radical or by the sequestering of iron. Alternatively, the sulfhydryl groups in processed dairy products may also be presumably associated with antioxidant activity (Jocelyn, 1972; Chow, 1979; Taylor and Richardson, 1980a; Thompkinson and Mathur, 1989). Given our earlier findings of the sulfhydryl content and relative reducing activity in BMS (Figures 1 and 2), a likely explanation for the observed antioxidant activity of BMS in our model system would be the radical scavenging activity of sulfhydryl groups, or a reducing activity at higher concentrations. Furthermore, the iron chelating ability of BMS can also retard the onset of iron induced lipid peroxidation. Because there was no addition of iron to the model system and only trace amounts (e.g., $25 \mu \mathrm{g}$ of iron/g of BMS) were present, the sequestering activity would not be expected to be a primary factor in this particular experiment.

\section{CONCLUSIONS}

The antioxidant activity of the BMS at 0.1 and $0.2 \%$ was shown to inhibit lipid oxidation by 56 and $61 \%$, respectively, using a simple peroxidizing model system. This activity was attributed to a significant relative reducing activity of BMS at amounts exceeding $10 \mathrm{mg}$. The reducing activity in BMS was mainly attributed to the sulfhydryl content, present at a level as high as $28.79 \mu M$ BMS. In addition to having strong reducing activity, higher levels of BMS were also shown to scavenge $\cdot \mathrm{OH}$ in an aqueous medium produced by the Fen- 
ton reaction. This affinity of scavenging $\cdot \mathrm{OH}$ activity by BMS was contributed to both reducing and iron sequestering activities. BMS also had a significantly higher affinity for $\mathrm{Fe}^{2+}(55-95 \%)$ than $\mathrm{Fe}^{2+}(18-55 \%)$. In conclusion, the crude BMS powder was effective at producing an antioxidant effect by acting as a reducing agent to scavenge peroxide and hydroxyl radical, and sequestering both $\mathrm{Fe}^{2+}$ and $\mathrm{Fe}^{3+}$.

\section{ACKNOWLEDGMENTS}

The authors extend sincere appreciation to Dairyworld Foods for their generous supply of buttermilk solids and to BC Science Council for their GREAT Award to the author P.Y.Y. Wong. This study is funded in part by a grant from the Dairy Farmers of Canada.

\section{REFERENCES}

Allen, J. C., and W. L. Wrieden. 1982. Influence of milk proteins on lipid oxidation in aqueous emulsion. I. Casein, whey protein and $\alpha$-lactalbumin. J. Dairy Res. 49:239-248.

Aruoma, O. I. 1993. Free radicals in foods. Chem. Br. 29:210-214.

Basch, J. J., S. B. Jones, E. B. Kalan, and W. V. Wondolowski. 1970. Distribution of added iron and polyphosphate phosphorus in cow's milk. J. Dairy Sci. 57:545-550.

Chow, C. K. 1979. Nutritional influence on cellular antioxidant defense system. Am. J. Clin. Nutr. 32:1066-1081.

Colbert, L. B., and E. A. Decker. 1991. Antioxidant activity of an ultrafiltration permeate from acid whey. J. Food Sci. 56:12481250.

Demott, B. J., and B. Dincer. 1976. Binding added iron to various milk proteins. J. Dairy Sci. 59:1557-1559.

Demott, B. J., and J. R. Park. 1974. Effect of processing milk upon association of added iron with different protein fractions. J. Dairy Sci. 57:121-123.

Duh, P. D., and G. C. Yen. 1995. Changes in antioxidant activity and components of methanolic extracts of peanut hulls irradiated with ultraviolet light. Food Chem. 54:127-131.

Ellman, G. L. 1959. Tissue sulfhydryl group. Arch. Biochem. Biophy. 82:70-77.

Halliwell, B., J. M. C. Gutteridge, and O. I. Aruoma. 1987. The deoxyribose method: A simple "test tube" assay for determination of rate constants for reactions of hydroxyl radicals. Anal. Biochem. 165:215-219.

Hekmat, S., and D. J. McMahon. 1998. Distribution of iron between caseins and whey proteins in acidified milk. Lebensm. Wiss. Technol. 31:632-638.

Hutton, J. T., and S. Patton. 1952. The origin of sulhydryl groups in milk proteins and their contribution to "cooked flavor". J. Dairy Sci. 35:699-709.

Jaswir, I., Y. B. Che Man, and D. D. Kitts. 2000a. Effect of natural antioxidants in controlling alkaline contaminant materials $(\mathrm{ACM})$ in heated palm olein. Food Res. Int. 33:75-81.
Jaswir, I., Y. B. Che Man, and D. D. Kitts. 2000b. Synergistic effects of rosemary, sage and citric acid on fatty acid retention of palm olein during deep-fat frying. J. AOCS 77:527-533.

Jocelyn, P. C. 1972. Biochemistry of the SH group. Academic Press, London, UK.

Kellogg III, E. W., and I. Fridovich. 1975. Superoxide, hydrogen peroxide, and singlet oxygen in lipid peroxidation by a xanthine oxidase system. J. Biol. Chem. 25:8812-8817.

Lee, F. A. 1983. Milk and milk products. Pages 363-375 in Basic Food Chemistry, 2nd ed. AVI Publ. Co., Wesport, CT.

Mahoney, J. R., and E. Graf. 1986. Role of $\alpha$-tocopherol, ascorbic acid and EDTA as oxidants in model system. J. Food Sci. 51:12931296.

Maté, J. I., E. N. Frankel, and J. M. Krochta. 1996. Whey protein isolate edible coating: Effect on the rancidity process of dry roasted peanuts. J. Agric. Food Chem. 44:1736-1740.

McMahon, D. J., and R. J. Brown. 1984. Composition, structure, and integrity of casein micelles: a review. J. Dairy Sci. 67:499-512.

Nutting, G. C. 1970. The byproducts of milk. Pages 1-23 in Byproducts from Milk. A. J. St. Angelo ed. AVI Publ. Co., Wesport, CT.

Oyaizu, M. 1986. Studies on products of browning reaction: Antioxidative activities of browning reaction prepared from glucosamine. Jap. J. of Nutr. 44:307-315.

Patrick, P. S., and H. E. Swaisgood. 1976. Sulfhydryl and disulfide groups in skim milk as affected by direct ultra-high-temperature heating and subsequent storage. J. Dairy Sci. 59:594-600.

Richardson, T., and M. Korycka-Dahl. 1983. Lipid oxidation. Pages 244-309 in Development in Dairy Chemistry. Vol. 2. Lipids. P. F. Fox, ed. Appl. Sci. Publ., London, UK.

Stuchell, Y. M., and J. M. Krochta. 1995. Edible coating on frozen king salmon: Effect of whey protein isolate and acetylated monoglycerides on moisture loss and lipid oxidation. J. Food Sci. 60:28-31.

Taylor, M. J., and T. Richardson. 1980a. Antioxidant activity of skin milk: Effect of heat and resultant sulfhydryl groups. J. Dairy Res. 63:1783-1795.

Taylor, M. J., and T. Richardson. 1980b. Antioxidant activity of cysteine and protein sulfhydryls in a linoleate emulsion oxidized by hemoglobin. J. Food Sci. 45:1223-1227, 1230.

Thompkinson, D. K., and B. N. Mathur. 1989. Effect of buttermilk solids and methyl siloxane on the oxidative stability of lipids in a PUFA-rich infant formula. Ind. J. Dairy Sci. 42:391-393.

Vaughan, O. W., and R. E. Knauff. 1961. Chemical state and nutritional availability of iron in a prepared infant formula. J. Dairy Sci. 44:1650-1654.

Vercellotti, J. R., A. J. St. Angelo, and A. M. Spanier. 1992. Lipid oxidation in foods, an overview. Pages 1-14 in Lipid Oxidation in Food. A. J. St. Angelo ed. Am. Chem. Soc., Washington, DC.

Wijewickreme, A. N., and D. D. Kitts. 1997. Influence of reaction conditions on the oxidative behavior of model Maillard reaction products. J. Agric. Food Chem. 45:4571-4576.

Wijewickreme, A. N., and D. D. Kitts. 1998. Oxidative reactions of model Maillard reaction products and $\alpha$-tocopherol in a flour-lipid mixture. J. Food Sci. 63:466-471.

Wong, P. Y. Y., and D. D. Kitts. 2001. An iron binding assay to measure activity of known food sequestering agents: studies with buttermilk solids. Food Chem. 72:245-254.

Yen, G. C., and H. Y. Chen. 1995. Antioxidant activity of various tea extracts in relation to their antimutagenicity. J. Agric. Food Chem. 43:27-32. 